\title{
The Ethics of Survival: Responsibility and Sacrifice in Environmental Ethics
}

Ilan Safit, Pace University, New York, USA

Email: isafit@pace.edu

\section{Abstract}

The primary concern of environmental ethics pushed to the limit is the question of survival. An ethic of survival would concern the possibility of morality in an environmental crisis that promises humanity immeasurable damage, suffering, and even the possibility of species extinction. A phenomenological analysis of the question of moral response to such future catastrophe reveals - in Heideggerian fashion contraHeidegger - that the very question positions us in a relation of responsibility towards a world and a humanity that lies beyond one's reach and extends into the future. Responsibility, then, arises as a constituting element that defines humanity and therefore cannot be bracketed away or suspended in a time of crisis. Through a reading of Hans Jonas' notion of responsibility and a critique of some major notions of Environmental Ethics, this article argues that an ethic of survival is conditioned by the survival of humanity as a moral, responsible species. The main challenge of this responsibility is further suggested to be the clash between the autonomy and dignity of the individual and the vital needs of the larger community in the struggle for survival.

\section{Introduction}

There is a question of life and death underlying all concerns of environmental ethics. At the same time, life and death often form the limit case against which ethical codes fail their practical test and find themselves suspended, at least until the danger passes. These are two reasons for environmental ethics to look death in the eye and define itself in direct relation to death's threat, not only to life, but also to morality.

The concerns of environmental ethics - whether they address the well-being of the biotic community, the integrity of land and ecosystems, the fate of endangered species and the threats to biodiversity, or the very question of the future of humanity on a life supporting planet-are all, at base, ontological issues, as they are concerned with the being of living and non-living beings. The range of concerns stretches from integrity of being to the very possibility of a future existence. If the general scope, then, is ontological, it comes with a twist: in the face of a rolling ecological crisis, the ontological question becomes a question of survival.

But, if the ground of being is survival, the ground of ethics - as the discourse involved in framing codes of right conduct-is morality. Morality, i.e. the distinction 
between right and wrong in a sense all of its own, must inform the ethics of survival, which is environmental ethics, if the aim of ethical discourse is indeed to formulate a new ethic rather than just a practical strategy for overcoming the threats of an ecological catastrophe. A strategy of survival is in need of an ethic of survival if we want to avoid the kind of ruthless solutions with which generals aim to end a war.

Given that life is at stake, that the issues involved are issues of survival, the ethical and ontological questions converge as existential ones. Environmental ethics, then, is seeking an existential ethic, that is, a frame of conduct for survival, which has morality built into it. This means, the renewed ethic we are seeking should be able to offer an understanding of the moral obligations of humanity as something more fundamental than 'doing the right thing'. Rather than a matter of privileged choice, morality in such a context becomes an existential necessity; a necessity in the sense that it would be impossible for humanity to exist otherwise. In other words, if morality informs the ethics of survival, we will have to proceed with an understanding of the human being as a moral being who strives to preserve both life and morality. That is, who strives to survive as a moral being. It is through the notion of responsibility, as developed by Hans Jonas (1984), that we shall give form to this question here. And we shall try to go beyond Jonas by asking about the position of the individual in the difficult engagement of ethics and ecology.

The expansion of the scope of ethical inquiry, as all environmental ethics understood from the start, changes the matrix within which an ethic is formulated. The first change, and this is clear in the very first lines of Aldo Leopold's "Land Ethic" (1949, 1987) and in the very first moves of the Australio-Anglo-American philosophers that have established environmental ethics' academic field, moves away from the narrower, "old" ethic, focused only on the well-being of (certain) human beings in human society. But in doing so, in re-negotiating the anthropocentrism of traditional ethics, we do not want to forget that the new ethic, even as it departs from the human experience to larger levels of community and existence, is still formulated by humans and for human conduct. As such, our ethics will always be anthroposcopic - arising from a human view of the world - even as the view of both world and the place of humanity within it shifts or aspires to some kind of "objective" overview in which subjective interests are suspended. Secondly, we will need to remember that there is a consequentialist dimension to the project of this ethics, even as it may interact with the other major paradigms of ethical inquiry: the anticipated environmental catastrophe that has triggered the quest for an environmental ethic also posits a desired consequence of averting such catastrophe. This is yet another sense in which Environmental Ethics comes to renew Ethics as a whole, by exposing the collaborative relation between what appears to be opposing approaches, specifically deontology and consequentialism.

If what underlies the ongoing ecological crisis is the uncontrolled growth of human practices and population, the responding course of action needs to be the curbing of both by artificially introducing to human practices what Thomas Berry has called the “ecological law of limits" (Berry, 2000, p. 92). An ethic of self-imposed limits and limitations would seem to come in immediate conflict with the evolution of humanistic ethics and its steady focus on securing and expanding the liberties of individuals, which, in turn, define the individual's well being. The ethical dilemma of the new environmental ethics, then, revolves the possibility of replacing a humanistic, individual-based ethic 
with a community based ethic, an ethic which would pose restrictions on the liberties of individuals, even would demand of individuals' sacrifices that are currently regarded oppressive and immoral. The negotiation of these two kinds of ethics is the central task of the new environmental ethics.

We are seeking, then, the beginning of an understanding of an ethic grounded in existence, addressing the moral question of human life in relation to a larger ecological community without losing track of the position of individuals within the matrix of this ethic. We shall not lose track of the individual if we remind ourselves that an ethical inquiry that seeks to conclude with the formulation of obligations mandated by an "ethical commandment" must conclude with an individual, a self, who issues such a commandment to her- or him-self. All other commandments, all other obedience to commandments issued by sources other than the self, would simply be a following of orders. However, there is nothing moral as such in obeying orders, even if Socrates might have momentarily proposed otherwise.

If the concluding point, the point from which moral commandments are issued and (sometimes) translate into action, is one's own self, then a good place to start would also be the self, the self that is asking the question of morality in relation to existence. In other words, we find ourselves at the doorstep of phenomenological inquiry. And so, we start again, proceeding by following a phenomenological model of inquiry whose starting point is existential reflection, while each reflection is also reflexive and brings into question the position from which the question is being asked. In doing so, we will be staying close to the main source of inspiration of this investigation, the post-Heideggerian phenomenological thought of Hans Jonas.

\section{An Ethic of Survival: A Phenomenological Approach}

Environmental Ethics, rather than being a sub-field of applied ethics, opens a unique opportunity for re-examining and renewing the most general or most fundamental of ethics. This becomes clear when the wide range of environmental concerns is narrowed down to the one of sustainability: the ability of the planet to continue sustaining the existing variety of life forms, including human life. Such a concern is informed by the current and projected ecological impact of a growing human population and the increase in consumption, pollution, and material depletion. In other words, we are still engaged with the concerns raised by the empirical and statistical data introduced by the 1972 book, The Limits to Growth, (Meadows, Meadows, Randers \& Behrens, 1972), become the concerns of environmental ethics in its narrow sense. This sense both narrows down the environmental scope to its human members-not simply as the only ones that matter, but as the ones who are asking, answering, and listening to the ethical concerns-and further, brings the case of environmental danger all the way to the limit with the possibility of the annihilation of humanity, even if such a scenario of complete doom is not the most likely one. The narrow sense of environmental ethics focuses, then, on nothing less than human survival on planet earth. And, as an ethics, environmental ethics becomes an ethics of survival.

An ethics of survival, not a strategy for survival, and as an ethics, its task is to ethically rethink the human condition within the context of global survival. Empirical world conditions and their projected advancement into the future-an advancement as 
deterioration-frame the question of this human condition in a fashion that brings a metaphysical inquiry down to earth. As a response to real world conditions, humanity is called to reevaluate its place in the world, its effects on the world, and its obligations towards the world in which it finds itself. Finding itself in the world, and finding the world in bad shape, humanity's response to the ethical question is already framed between its being in the world and its response to the threats to this being. In other words, the question of environmental ethics in its narrow sense already grounds the ethical in the existential; it grounds ethics in existence. Hence, the narrow sense of environmental ethics expands back to the full sense of Ethics proper. Ethics proper is understood here as that which defines the human outlook from the start, that which starts out with a view of what it means to be human in this particular world. This is a view of ethics that insists that moral consideration is not an afterthought in the project of understanding the condition of being human. Instead, moral consideration is posited from the start as constitutive to the prism through which humans see themselves in the world.

Accepting that this particular world is undergoing an ecological crisis, humanity finds itself in a necessity to respond to this crisis. While this necessity to respond is an existential necessity, a life-preserving necessity, it is not the experience of an immediate danger to my life that prompts the response, and it is not my own life which I strive to protect and preserve in responding to the threat. Instead, it is a threat to a community larger than myself and that extends into the future. In other words, even as an individual, this individual, poses the ethical-existential question, the response to the question immediately expands beyond the individual's confines, and specifically beyond the temporal confines of an individual concerned only with his or her contemporaries.

The compulsion to respond to such a distant danger that lies beyond my own existence illuminates a fundamental feature of being human, namely a responsive feature or the feature of responsibility. Responsibility as that which originates immediately from the confrontation with a projected existential crisis reveals itself as a defining feature of human existence: the human being as a responsible being is a formula of a fundamental ethic grounded in existence. It provides for us an ethos that springs up directly from the existential condition, or rather directly from the realization of an existence in a world under threat. Precisely because it goes beyond one's self, projected towards the being and well-being of a larger community, and a community that is neither immediately here nor immediately now, this response already assumes responsibility, is already an ethic which understands one's being in relation to the being of others, an understanding of being as a relation which is binding. Responsibility, in this sense, both assumes and declares individual human existence as relational, being-in-relation-to-others, including others that are not immediately present. One might claim that an ethics of responsibility appears in its "most ethical" form precisely as a relation to those who are not present, as such a relation could not be reduced to existential utility or to a vested interest that will profit me and my existence here and now. (The genetic interest of self-propagation trough one's progenies can be bracketed here as its benefits are deferred beyond my death; they will not be part of my experiences. This does not come to deny the force and value of both biological and cultural interests in self-propagation but only to show that they do not belong to the kind of individual existential concern for that which will benefit me in my lifetime.) 
The ongoing phenomenological analysis might want a more concrete, phenomenological description of an embodied experience that would produce the structures of responsibility just described, but this might prove tricky. The ambitious context of our investigation extends far beyond a single experience and far beyond a single life: precisely because it is informed by and directed towards the possibility of a catastrophe lying in the future, and because the ethical import discovered is dissociated from personal interest in my own well being, it would be hard to correlate a concrete experience to that which arises from the contemplation of the projected significance of the various symptoms of environmental degradation and their anticipated outcome. But let us try.

Climate change is an aspect of the ecological crisis that has been receiving perhaps the most popular attention. Of course it cannot be observed in a single act nor fully experienced through any of its symptomatic events and traces: a warmer winter, an extreme storm, a local disaster, an eroded coastline. All these would feature as isolated experiences, only the patterning of which into a meaningful series and the scientifically informed implication of such patterns for the future will produce the prediction of their eventual outcome: the rise in sea level that would cause the flooding of low lying land; the destruction of plant, animal, and human life and the drowning of land effected by such change; the expectant displacement of human populations upwards of 150 million; the immediate suffering and geo-political turmoil that will result of such displacement; the acts of atrocity to be expected from individuals and from governments facing such challenges...

And yet all these are acts of the imagination based on events that cannot be convened into a single experience. Still, let us take an experience that comes as close as possible to a direct observation of climate change. For this we need to revert to cinematic mediation, which, as I have tried to demonstrate elsewhere (Safit, forthcoming), is a legitimate and even extremely efficacious tool in ecological phenomenology. We turn to Chasing Ice (Orlowski, 2012), a documentary film that follows the efforts of photographer James Balog to capture images of melting glaciers in different locations in the Northern hemisphere. Balog places scores of still cameras in the arctic landscape, later compiling hundreds of thousands of single images into time-lapse strips that visualize a yearlong melting process in mere seconds. With further aid of editing technology, he is able to visualize the rate of the melting in comparison to previous decades and centuries. Finally, a video image captures the calving of a glacier the size of Manhattan, confronting the viewers with the direct sight of a geological event of monumental scale and that usually is given only in the form of prediction or evidenced as something that has occurred in the past. The images are overwhelming; the enormity of the visible geological transformation trumps any description, and the rhetorical impact of a "true to life" documentary footage surpasses any impression of a fictional disaster movie. The images support the claims of a climatological theory. The experience they produce correlate to a theoretic and informative frame provided by climatology.

And yet, even with the time-lapse imagery that condense a year into a few seconds, and even with the titanic images of the calving glacier, what is experientially given is an event neither with its anthropogenic causes nor with its ecological future effects on humans, other life forms, and the environment as a whole. Furthermore, the viewing experience, proportionally colossal in relation to the "colossality" of what is viewed, is, at 
bottom, an aesthetic experience, not an ethical one; it stimulates a sense of awe, fear, and impotence, not of responsibility.

This is neither a critique of the filmmakers nor of the power of images; no claim is intended here against the possibility and capacities of a cinematic ethical impact or its contributions to a phenomenological inquiry, including to a phenomenology of ethical response. Instead, my claim is that the phenomenological discovery of responsibility in response to the symptoms of an impending ecological catastrophe depends on a "picture" in need of a scale that cannot be given in a single, embodied experience. It is through the theoretical gathering of various causes, a variety of events, and a projection of effects, that our phenomenological reflection meets the given which produces the response of responsibility in this particular case.

Trafficking between the poles of life and death, our investigation discovers that neither life nor death are experiential "poles," that life is a whole without an opposite, and that death, my death, as Wittgenstein surprisingly observed (Wittgenstein, 2000), is never given to me in experience. In other words, it is not in experience but in reflection that we shall encounter the full picture that produces the structure of the ethical responsibility invoked by environmental concern.

Returning, then, to the reflection that extends beyond immediate experience, that finds responsibility precisely as a response to a non-experience, to an experience of the future and of others, we note that it does not arise as a "moral consideration." Instead, responsibility arises as a response - a response to existential threats-contemplated now, to be experienced in the future. As such, it appears to define what we are from the start: projected responsibly beyond the self into a larger community, beyond the present into the future. Responsibility emerges as an understanding of the Being from which morality is generated. Thus a matrix of morality is already set by the notion of responsibility as a self-projection into at least two parametric pairs: Individual-Community, Present-Future. With this matrix we can see how already one preliminary question of academic environmental ethics is removed from the table: the question of responsibility to future generations. This responsibility is already at work in the very response to the danger ahead, and the question becomes moot.

\section{Considerability and Intrinsic Value}

But this is not the only preliminary question of environmental ethics that proves moot once a phenomenological approach is taken. The academic field of environmental ethics sprouted in the early 1970s with the twin questions of moral considerability and of the intrinsic value of nature, or which could be found within nature. Both questions stem from the initial approach that sought to expand an existing morality so it would apply to entities previously excluded from moral consideration. The search for a new criterion for moral considerability immediately enacted the postulation of the ethical tradition, which holds that for a thing to be morally considerable, it has to have a value all of its own, an inherent or intrinsic value. Hence environmental ethics took off on a wild goose chase that is not entirely over.

I would like to suggest that framing the new ethical questions in these terms exposes a fundamental problem with the old approach to ethics from which the terms are borrowed, the approach that demands intrinsic value from the "moral patient" in order to 
justify its status as morally considerable. Even as academic environmental ethics has been obsessing about these questions during the first two or so decades of the field's existence, it has at the same time demonstrated, tacitly at times, the need to move away from such ethical thinking that places the onus of morality on its recipients. Instead, we need to acknowledge that morality and its ethical dictums lie fully with the thinkers and doers of morality. An understanding of the misunderstandings engrained in these questions would carry us further into a new environmental ethics.

The question whether non-human nature is or needs to be morally considered was raised in the founding paper of academic environmental ethics, Richard Routley's 1973 "Is there a need for a new, an environmental ethic?" This question led immediately to the question of nature's "intrinsic value," and a new academic field was generated. Yet, I would like to suggest, if what is sought here is nature's moral value, the question would make philosophical sense only when posed from the other direction, from the direction of the questioning subject, taking into consideration that it is the subject doing the considering - the questioning and the answering - of "moral value" in relation to nature.

An influential article in the early phase of academic environmental ethics, Kenneth Goodpaster's “On Being Morally Considerable” (1978), is famous precisely for reversing this consideration, moving the focus away from the considering subject to the considered object, from the "agent" who wishes to act morally to the "patient" receiving the moral attention of the agent. Goodpaster poses the question-What should we consider morally?-And proceeds to search for a criterion that would determine the answer to this question and designate the expanded class of morally considerable entities. By picking up Aldo Leopold's initial move, introduced thirty years earlier in his pioneering "The Land Ethic” (Leopold, 1949), Goodpaster has proposed what could appear as a revolution in ethical thinking. But this revolution is misguided in several ways. For Example, as Thomas Birch suggested, the supposedly ethical position from which a criterion of considerability is sought is a self-claimed elevated position, from which the thinker seeks to include new entities in the moral class, while assuming the power to exclude others from such a class, to which, it seems to go without saying, the thinker already belongs (Birch, 1993, pp. 315-317). What we see in Goodpaster's move is a reversal of an inwardly ethical reflection (for example, What must $I$ be in order to be ethical?) to a question of outward projection (Who deserves my moral consideration?). But, as we shall see next, inwards reflection serves as the grounds for projection, and hence precedes it. Viewing the ethical question in a phenomenological mode will restart the ethical investigation from a different ground, where the very act of questioning illuminates the starting point as a position that already supplies certain knowledge. For the question of nature's moral considerability reveals something about the one who is asking, a human, and hence about humanity. The question-we may say in Heideggerian fashion-reveals that humans are a kind of beings that ask questions about moral considerability. And it is a human who is both asking and answering this question. As a question, it is an intrahuman affair, even as it projects humanity morally into the more-than-human world. What we find illuminated by the answer lying in the very question-namely that it is the anthropos who is viewing the issue-is not simply the anthropocentric foundations of moral consideration but rather its anthroposcopic outlook: humanity looking out at the world guided by a moral quest to see the world morally. By so doing, humanity constitutes itself, morally, in this world it sees, by seeing the world in moral terms. 
Morality, as a distinction between right and wrong in a sense all of its own, opens up a view onto the world before the world itself even comes into view. This distinction is not to be found in the world - which might hold inherent distinctions between stability and instability, health and sickness, life promoting and life hindering, but cannot be said to contain a moral distinction of good and bad prior to the human introduction of this distinction. The moral distinction is imposed onto the world, or the world is seen through the moral prism. Regardless of what I will find in the world, I already prepare myself, project myself to see it morally, to consider it morally. Hence, the answer to both questions: what is morally considerable? what should I consider morally? is already given by the moral prism through which I am viewing the world: the whole world, or at least all of that which is revealed to me in sight or thought. As morality lies in the way I see the world, I shall consider morally everything in the world. Phenomenologically, this means that what has been revealed is an inner structure of our own thinking, now turned into content and theme, into the question of my responsibility towards what is observed. On the one hand we have a question directed towards action, on the other an ethicalexistential structure that establishes my being-in-the-world through the general relation of responsibility.

If this is the case, if in addressing the world morally the world in all its facets and inhabitants will appear to me from the start as the place in which I exercise morality, just as a physical world is the place in which I exercise my physicality, then there is no need to find in the world the justification for my moral behavior. There is no need to find in the world the value that will compel me to treat the world morally if I am already bringing moral value along with me, projecting it onto the world with the anthroposcopic view that is morality. (See also Brown (2003) for the claim that phenomenological observation already includes valuing in the intentional act, implicating both observer and observed in this valuing.)

With this line of thinking, we dismiss not only the question of moral considerability but also the other founding question of old environmental ethics, the question of nature's intrinsic value. The centrality of this question-asking whether nature has its own inherent and objective value, or whether humans are the only ones who either have intrinsic value or that can confer value upon an objectively valueless world-was noted early on by Tom Regan: "The development of what can properly be called an environmental ethic requires that we postulate inherent values in nature” (Regan 1981, p. 34). And J. Baird Callicott repeats this claim as he summarizes twenty years of the debate: "The central theoretical question in environmental ethics," Callicott writes in his critical analysis of the question, is whether in "addition to human beings [...] nature (or some of nature's parts) have intrinsic value?" Hence "the defining problem for environmental ethics" is "how to discover intrinsic value in nature” (Callicott, 1999, p. 241).

The history of this debate has been summarized several times as it was unfolding, see for example, Callicott (1985, 1999) Light (2002), Palmer (2003), the articles collected in The Monist (Callicott, 1992), as a special issue on the subject, as well as in part III of Light and Rolston (2003). Krebs (1999) offers a systematic exposition of the arguments for nature's intrinsic value. With such a historical background, one would hesitate to reenter a dispute that seems to have exhausted itself as well as its participants, even if we note a recent revival of interest in the question (McShane, 2007; Samuelsson 2010). And 
yet, it would not be imprudent to ask whether environmental ethics or the old ethics by which it was originally informed actually address moral value when invoking the term "intrinsic value." It seems proper to ask for the very meaning of "value" in the environmental ethics that stakes so much value in and/or of nature.

It is true that the notion of a moral intrinsic value stems from the Aristotelian and Kantian grounds of the "end-in-itself," and "good of its own," an autotelic Good that ethical theory has taken as the fundamental condition for moral consideration. But is the "value" which is the self-motivated process of reaching one's natural end, even when that end is life itself, the same value denoted by the term "moral value"?

There is easily something confusing, misleading, in the move from "good" to "value" in ethical discourse, which is, so at least we expect, informed by morality. Holmes Roslton III, probably the staunchest proponent in academic environmental ethics of the notion of an inherent value within nature, independent of human evaluators, is very much aware of this, as he states, "Evaluating Earth, the appropriate category is not moral goodness, for there are no moral agents in nature; the appropriate category is some one or more kinds of nonmoral goodness, better called its value, its worth” (Rolston, 1999, p. 360).

But, can we truly dissociate "value" from morality in the ethical discourse? Even with such caveats and clarifications as the one quoted above, there is a rhetorical import to the ambiguity or polysemy of "value" that cannot be overlooked and is in need of clarification.

Moral values are the set of ideal principles that a community holds to be right, good, and just. They serve as foundations to a worldview and ideally set a certain set of guidelines to individual and societal conduct. In the traditions of both virtue ethics and deontology, these principles are indeed set as good in themselves. They serve to hold in check one's personal inclinations, desires, and interests by making a distinction between these and the principles of morality, sanctioning the priority of the latter. In this sense, moral values are foreign to the notion of interest. Moral considerations should be conducted from a dis-interested standpoint, as they do not come to promote and protect the needs and wishes of the individual or the group, aside from the wish to be "good" according to the ideal principles of morality. This means, morality is not set up to protect my interests, including the interest of my own protection. Morality, then, cannot be appealed to for self-protection. Instead, if we accept as axiomatic that morality dictates the reduction of suffering in the world, we will discover that the only appeal to protection that involves a dis-interested consultation with moral value would demand of me to protect the other, to promote the well-being of others.

Consequential ethics, by starting out from the results of action, reverses the direction of goodness. Indeed, environmental ethics has originally been motivated by a strong consequential bent of preventing the deterioration of the natural world by repairing our relations with nature and changing our attitudes towards it. But this noble goal reenacts the basic conceptual and terminological flaw underlying all consequential ethics. For consequential ethics, starting from the end, evaluates means and measures their outcome. By doing so, consequentialism enacts an economic model of costs and benefits in which "value" has a different meaning altogether from the moral one. Indeed, if the dictionary meaning of "value" offers one or two definitions in terms of "highest regard," "standards" and "ends-in-themselves," it also suggests a slew of other definitions, all 
based on the notion of "worth," which means the exchange rate of the thing evaluated. Focusing on such worth, such principle of exchangeability, consequential ethics of all kinds proceed by mere computations that answer a mathematical question and extracts "value" from its non-negotiable position. Consequentially, every value has its price.

Through the very notion of evaluation, then, moral value has been devalued. That is to say, if morality is based on a set of cherished principles held in the highest esteem that merits their name as values, then consequential ethics has always been engaged in devaluating the value of these moral values. If held in the highest regard, moral values cannot come with a measure or an exchange rate; they are, as the famous credit card advertisement aptly puts it, priceless.

The priceless, if its name is to be trusted, cannot be measured by degrees ascending from the cheapest to the priciest. The priceless is outside the scale of prices; it is dearer than all that which has a price. Having been fixed in their special position, priceless moral values cannot be traded without losing their value altogether; their evaluation, in fact, is a devaluation, a violation. We either uphold a value or suspend it altogether, as we often do in our daily practices, often choosing to go with what is practical, profitable, or least taxing in other ways. This suspension does not undermine their meaning and position; it testifies to the extent they have a hold on our will, or that the will has on them to follow them in practice. If such velleities are recurrent or symptomatic, we will have to admit that moral values do not guide our actions, and we will have to articulate the implications of such a realization. But even in such a case, the first requirement of the philosophical discourse called "ethics" is for the conceptual clarity that will assure that we know what we are talking about when we are talking about moral values. Without such clarity, we will easily find ourselves confusing fixed moral principles with rates of exchangeability and proceed to make ethical claims based on economic, rather than moral, principles.

The academic discourse of environmental ethics, from its intrinsic value debate to the terminology of "competing values" or even "environmental values" has often been riding this ambiguity of "value," with the result of producing a discourse that addresses preferences, priorities, interests, and functional instrumentality in which no moral question is involved. Such an approach confuses a moral question with a practical one and divorces itself from the ethics that give voice to an ethos, grounded in moral principles while directed at the world of action.

In addition, and very briefly, we should note the problematic notion of introducing to the ecological context a value that is claimed to be intrinsic. If the value that is intrinsic denotes, according to G.E. Moore (1922), an inherent, non-relative, noninstrumental and hence non-relational feature of the thing considered having intrinsic value, this view immediately clashes with what ecology offers as a conceptual paradigm. Ecology studies the lives of organisms in relation to their habitat and the web of living and non-living entities cohabiting in this habitat. This means, then, that no organism, no entity or act, has meaning - and hence no value, as Rolston recognizes (e.g., Rolston, 1991, p.83) — outside of the set of relations that constitute the ecological model from the start. Ecological thinking, as a model of thinking in terms of relations, seems to reject the notion of the independently intrinsic altogether! (See also Kagan (1998) for a critique of the notion of intrinsic value and the impossibility of a strong distinction of intrinsic value from the notion of "instrumental value," against which it is often pitted.) 


\section{The Incompatibility of Ecology and Morality}

The ecological model, in its encounter with ethical discourse, brings into question the position of the individual within the environmental whole. If we started out our discussion in dramatic terms by claiming that what underlies environmental ethics is a question of life and death, and our inquiry proceeded to focus on the place of the individual within environmental ethics, we have to note now that within the context of natural ecology, the death of individuals is vital (in both senses of the word); it is lifefurthering. The lioness hunting down the antelope, the wolf separating the lamb from the flock, the pack of tigers that jump a baby elephant, the baby penguin pecked alive by a skua, the killer whale biting a seal in half - all these form horrendous images that are heart breaking to a human eye, but at the same time a necessity and a fact of nature. Ecologically speaking, what culture names "an individual” is food, the nourishment for animals, plants, and the soil itself. Here, the death of an individual is not the opposite of life, which, itself, on the ecological scale, stands for the very dimension of the whole. In fact, it is more in death by predation than in life that the individual organism is ecologically valuable - that is, ecologically functional, by furthering the webs and cycles of the life of the whole. Indeed, it is by its very functionality, rather than by being a subject of life, that the individual is ecologically measured, whether it is the function of producing more living beings or the function of feeding other living beings in its own death.

Erazim Kohák (2000) recognizes the contrast between the ecological whole and the position of the individual in his sympathetic appraisal of Aldo Leopold's Land Ethic. "Leopold really goes against the current of contemporary ethics,” Kohák writes. "That ethics is individualistic, dealing with individual demands or 'rights' and their balancing" (Kohák 2000, p. 91). But, individualistic ethics "do not take into account the needs and interests of social wholes and long-term processes” (p.91-92). Within the context of the life of the whole and the death of individuals, Kohák states, "to accept death as a necessary part of life is the difficult challenge today” (p.93).

This suggests that the comparative positions of the individual in the contexts of natural ecology, on one hand, and a cultural individual-based ethics, on the other, exposes an incompatibility that goes beyond the possibility of resolution through negotiation between competing approaches. Ecology sanctions the life of an individual as expendable, elevating its mortality over its vitality. An ethics focused on the individual, however, seeks to protect the individual's rights, and foremost its right to life.

Furthermore, we can detect a formal incompatibility of ecology and this kind of morality: The defining matrix within which morality operates is binary: a distinction between good and bad, right and wrong. "Ecology," on the other hand, designates a nonbinary whole, the whole that is Life without a real opposite. (It is not death but total annihilation that could be considered as candidate for such a position, but total annihilation cancels out not only all life, but also all oppositions and all significance.) In addition, the distinctions made by morality's binary matrix are in the realm of meanings, the unique kind of meanings invented by morality and the special significance it has created for the terms "right” and "wrong," "good” and "bad.” Ecology, however, measures or "evaluates" things according to their functionality in furthering the life of the 
whole. In other words, morality asks of things what do they mean, where do they fit within its two available categories of meaning, whereas ecology asks of things what do they do, what do they do for the furthering of life.

So it is also for the question of life and death underlying all ethical concerns and the morality that underlies it: this question, we can now further qualify, addresses the meaning of death, and of life, in our experiences and the cultural codes that shape them; it does not address the facticity of life and death.

In the moral, cultural context, the meaning of the death of an individual would (in most cases) spell tragedy. This is what is at stake here for morality - not the fact that there is death, but the meaning of death as tragedy, an undesirable outcome, and a moral "bad". And it is in this sense that we further recognize a dissonance between ethics and ecology, where that which is a vital function in the latter features negatively in the former. In the sphere of action, towards which ethics is directed, this means a conflict between the moral prohibition against murder and ecology's license to kill in the service of life. An ethics of survival that would like to take its cues from ecology risks falling into fascism that elevates the whole over its constituent individuals to the point in which the killing of individuals becomes justifiable. The risk taken by the very notion of "an ethics of survival" is that it can open up into the either/or choice between survival and ethics, presented at the limit as the choice between murder and suicide.

Our discussion - aimed at an exploration of morality in relation to ecology in the context of life and death-has reached an aporetic point that suggests the incompatibility of morality and ecology, due to their categorical differences in formal structure (one binary, the other a monistic whole), in application (the one dealing in meanings, the other in functions), and in their relation to death (tragedy in the one, a vital and productive necessity in the other). Moving forward, we will have to retreat from this confrontation of human morality with a more-than-human ecology. We will have to retreat back to the position in which we present human morality with its proper question: how to be human in face of the ecological whole and specifically in face of the ecological crisis. We will need help.

In retreating, we stop to formulate the terms of the problem of morality in relation to ecology as the conflict between individual's right to life and the needs of the larger ecological community, a community and an environment that subsists on the consumption of individual living beings.

\section{Hans J onas: Surviving Responsibly}

We seek help, then, in the formulations of Hans Jonas, who has been suggesting an ethics of responsibility since the time, at least, that Richard Routley (now Richard Sylvan) has opened up the discussion of academic environmental ethics in the Australian dialect of Anglo-American philosophy.

Hans Jonas, intellectually raised by Heidegger, matured with Hannah Arendt, and never having lost his reverence for Kant, moved on to acknowledge the advent of technology, its effects on the human-world condition and the need for a renewed ethics and a re-understanding of responsibility. Living through the mass destruction of WWII and writing in a time of cold war angst, Jonas notes that the new capability of total 
destruction calls for a new responsibility towards humanity's survival. This was first presented in the 1972 paper, "Technology and Responsibility: Reflections on the New Tasks of Ethics” (Jonas, 1973). Focusing on nuclear technology first, but expanding his purview to the incremental effects on the natural world of human production and consumption, Jonas moves back from the possibilities of global destruction to the need of a preventive "ethics of survival" motivated by a "heuristic of fear." The fear of the catastrophe, which humanity is able to cause by means of technology or as consequence of the modern life style, calls for the curbing of humanity's effects on the world as well as for the expansion of the scope of human responsibility to include the world at large. In the 1974 paper "Responsibility Today: The Ethics of an Endangered Future" (Jonas, 1976), later incorporated with "Technology and Responsibility" into the book Das Prinzip Verantwortung (Jonas, 1979), which was reworked into an English edition in 1984 as The Imperative of Responsibility (Jonas, 1984), Jonas employs Kantian terminology in offering an imperative for our time, anticipating the 1987 principle of sustainability formulated in the UN's Brundtland Report: "Do not compromise the conditions for an indefinite continuation of humanity on earth" (Jonas 1984, p. 11).

Let us take a close look at Jonas' core claim:

For the moment, all work on the "true" man must stand back behind the bare saving of its precondition, namely, the existence of mankind in a sufficient natural environment. In the total danger of the world-historical Now [,] we find ourselves thrown back from the ever-open question, what man ought to be (the answer to which is changeable), to the first commandment tacitly always underlying it, but never before in need of enunciation: that he should be-indeed, as a human being. This "as" brings the essence, as much we know or divine it, into the imperative of "that" as the ultimate reason for its absoluteness and must prevent its observance from devouring the ontological sanction itself; that is, the policy of survival must beware lest the existence finally saved will have ceased to be human. (Jonas, 1984, p. 139)

The survival of the human species becomes for Jonas the first commandment, an ethical-ontological commandment, which takes into consideration that humanity's survival is inseparable from the well being of the natural environment in which humans live. Moreover, Jonas' earlier identification, in the 1963 book The Phenomenon of Life, of the "defining property" of all organisms, all life, in metabolism, makes it quite clear that the life of living beings, including human beings, is made possible and is inseparable from their environment. Metabolism, Jonas states in a later work, means, "to exist by way of exchanging matter with the environment” (Jonas, 1996, pp. 88-9). The environment is acknowledged to be not only a condition of the life of the organism but also an essential part of its definition: "Organism and environment together form a system, and this henceforth determines the basic concept of life" (Jonas, 1963, p. 46), and "The exchange of matter with the environment is not a peripheral activity engaged in by a persistent core: it is the total mode of continuity (self-continuation) of the subject of life itself" (p. 76).

But, if the exchange of matter with the environment defines the life of the human being, we need to acknowledge that the implication of Jonas' principle of responsibility 
for the continued life of humanity also offers a defining characteristic of what kind of living being humans are. "For the moment, all work on the 'true' man must stand back behind the bare saving of its precondition,” Jonas states above, returning immediately to this point: "we find ourselves thrown back from the ever-open question, what man ought to be (the answer to which is changeable), to the first commandment tacitly always underlying it." But isn't the answer to this question of the what already provided by the task discovered? Isn't the existential call for the survival of a community larger than myself and ahead of me goes beyond the existential into the ethical, preceding the existential by an ethical call to responsibility? In other words, doesn't an ethic inseparable from existence also serve as a definition of the "what of man"- -as I have suggested earlier - the human being as a responsible being? Humanity discovers a defining aspect of its being in Jonas' own realization of its responsibility for perpetuating human beings, which are inseparable from the world. At the very least, the individual human entertaining this realization of responsibility, accepting this responsibility, commanding her to take on this responsibility, will have discovered her being as being responsible. This grounding of the ethical in the existential produces an answer to the ontological "what," an answer that illuminates the ethical as prior to the existential, a responsibility towards a humanity greater than me, which means that it comes before my own existence.

We should note that the ethical-existential commandment we find in Jonas is not a mere case of "is" turning into "ought," but a phenomenological analysis of the Being of human beings and their projection towards a future which is larger than their own. The Heideggerian matrix of this analysis goes beyond Heidegger in ascribing the ethical notion of responsibility to the structural relation to others and to the world that Heidegger names Sorge or "care" and claims to use "in a purely ontologico-existential manner" (Heidegger, 1962, p. 237. See pp. 235-241 for the analysis of "care”). And the projection toward the future, which defines the Being of Heidegger's individual human being, or Dasein, here becomes a projection towards the future of the species rather than of the individual.

Survival and perpetuation, which happens "naturally" in nature, or which has become the hegemonic understanding of nature since the acceptance of the Darwinian paradigm, is taken up consciously here, and the realization of its full meaning in consciousness turns this paradigm into a commandment: the commandment of survivalas-perpetuation. In this commandment, ethics meets both biology and ontology, or ontology is re-viewed ethically by viewing Being as a commitment and hence committing to Being (Cf. Jonas, 1996, pp. 99-112).

But, what about the individual in this obligation towards the species? "The right of the individual to commit suicide," Jonas writes, "is morally arguable and must at least for particular circumstances be conceded: under no circumstances has mankind that right" (Jonas, 1984, p. 37). Here, at least here, Jonas is protected from the accusation of ecofascism in allowing the individual the freedom of life, or, at the very least, the freedom of choice to end one's life. The concerned consideration of collective existence, the collective destiny of humanity as a species and of the biosphere as whole, can easily fall into the fascism in which the individual falls out of sight and is not considered. Even though the specific consideration conceded here is quite peculiar, accepting the moral right of the individual to choose death, it is also highly significant for the understanding 
of the relation individual-community within the imperative of the responsibility for human survival. Jonas' imperative, as is in Kant, is taken up by the individual but projected towards the whole. Unlike Kant's second formulation of the Categorical Imperative, this imperative is binding in regards to the individual's obligation towards the whole, but it is wavered in the context of the relation of the individual towards her- or himself. But this suggests that the categorical obligation to survival goes only in one direction, towards the species. In this ethics of obligation, the individual, in its position as "patient," is excluded from the imperative of responsibility, which is focused on species survival. In certain similarity to the ecological model we have observed earlier, the individual here is regarded as expendable.

Jonas would later be more explicit about the his approval of a temporary suspending of individualistic ethics for the sake of survival: in the essay "Toward an Ontological Grounding of an Ethics for the Future” (Jonas, 1996), Jonas states that the faith in the resurfacing of a humanitarian humanity renders "permissible, for the sake of physical survival, to accept if need be a temporary absence of freedom in the external affairs of humanity" (Jonas, 1996, p. 112). This is a bold declaration that politically accepts tyranny and philosophically re-positions existence as prior to ethics. At the very least, it hierarchizes ethics by setting a supreme ethical imperative for species survival, which subjugates the individual and his or her liberties, regarded as a secondary ethic, to this imperative of survival. Such a hierarchy smacks of wartime "emergency rules" that often turn liberal-democracies into something else and can cause sympathetic readers to lose their sympathy. But, if we find ourselves averse to this suggestion, we need to go back to the passage quoted earlier from The Imperative of Responsibility, where we will find the formula that may redeem Jonas from the accusation of eco-fascism and help our own efforts to find a common ground for individualistic ethics and an environmental ethic of survival.

Immediately following the imperative of human existence- "that he should be"comes the qualification: “indeed, as a human being” (Jonas, 1984, p. 139). The qualification "as," Jonas himself states clearly, is not a mere stipulation, but an introduction of the "essence" of humanity into the ethical understanding that decrees its survival. The syntactic ordering could easily come across as a weak synthesis: that humanity must survive and that it must survive as human. Such a reading puts the emphasis on survival as paramount and weakens the qualification of the human as essentially humane. A stronger formulation would reverse the order of the statement in order to underline its analytic nature: 'as human beings, humanity must secure its survival.' But what does it mean "as” human beings? How are we to understand the "human being" as which humanity is to survive? We have already found the answer earlier in noting the significance of the very raising of the question of responsibility: As responsible beings, humans have the responsibility to secure the survival of humanity.

"[T]he policy of survival," our passage concludes, "must beware lest the existence finally saved will have ceased to be human." Ceasing to be human would mean ceasing to be responsible, more generally: ceasing to be moral. And for a wider answer to the question of being moral, this new environmental ethics is directed back to the old ethics that has been formulating morality as the humanism that protects the individual from the tyranny of power, be that the power of the single tyrant or the power of the group. Advancing towards an ethic of survival in facing the incremental destruction identified as 
the ecological crisis, we do not fully discard of the old ethic, the old morality of humanism. Maintaining our morality in the struggle for species survival by setting limits to growth of production, consumption, and human reproduction, would mean-according to our back and forth between new and old ethics - upholding the autonomy of the individual while assuming, individually and collectively, a responsibility towards the whole. This is the "correction” we extract from within Jonas' text to the totalitarian implications detected in Jonas' own imperative.

If towards the end of the previous section we recognized that morality addresses the meaning of being, rather than the facts of ecology, then now we are able to round off an explanation: an ethics of responsibility suggests that the meaning of being human is being a responsible, moral being; it implies my responsibility towards other individuals, a responsibility which is not suspended even at the limit, which itself is the test case of life and death, my life and death. To betray this responsibility would mean to subvert the meaning of morality, to no longer understand morality or responsibility as the meaning of my being. Subverting the very meaning of my being would be no mere transformation but a metamorphosis in which I will no longer be what I am; I will no longer be what I've been before. My survival would not be "as a human being." In fact the "I" that I consider myself to be now will not survive if I allow myself the transgressions against the other, if I relinquish the upholding of her freedoms and the prohibition against his killing.

\section{Surviving Animally}

Aiming our inquiry at life and death, at identity and the loss thereof, we will find it difficult, in fact impossible, to produce a direct phenomenological description of the objects of our inquiry or of an experience in which the parameters of the inquiry appear as an encountered reality. We will need to turn to imagination, or, better still, to fiction, in order to concretize this inquiry through analysis of experience. We turn, then, to Yann Martel's novel, Life of Pi (Martel, 2001).

A story of survival through almost impossible environmental conditions, this literary work offers us, as readers, the ability to take in the expressed thoughts of the first person narrator as he encounters a reality that forces him to suspend his moral convictions in order to survive. The phenomenology of reading, as sketched out by Wolfgang Iser (Iser, 1974) and his recounting of the earlier analysis of Georges Poulet (Poulet, 1969), offers the understanding that in reading, a reader plays the author's words in her or his mind. This means that reading performs the ultimate intentional act of incorporating an exterior object into one's mental interiority that the words on the page, turning words in the reader's mind, become also the formal object or content of the reader's thought (Iser, 1974, pp. 292-294). In this sense, the words and/as thoughts of the first person narrator in Life of $\mathrm{Pi}$ would bring us as close as we would wish to get to a phenomenological description of an extended experience of a struggle for survival in the face of immediate mortal danger.

The novel relates the experience of a young boy, Pi Patel, who finds himself a castaway in the middle of the ocean, sharing a lifeboat with a carnivorous tiger named Richard Parker. Serving as a first-person narrator throughout most of the novel, Pi describes and expresses his emotions, thoughts, decisions, and actions that help him survive a period of 227 days on the boat and in the company of the dangerous tiger. A 
devout Hindu (as well as a Muslim and a Christian) $\mathrm{Pi}$ is a strict vegetarian at the beginning of the trip, when he and his family board a ship in India, on their way to Canada, accompanied by the remaining animals from their privately owned zoo. When the ship goes under and Pi finds himself the sole human survivor on a lifeboat crowded at first with several other animals, then left alone with the tiger, Pi forces himself to adapt his behavior and his diet in order to survive. He captures fish, then sea turtles, then sea birds, killing them with his bare hands and eating them raw.

The greater part of the novel narrates the efforts of survival and the inner strife of the character as he keeps himself and his dangerous companion alive. But the novel ends with an alternative version of the survival story, in which Pi, having been finally washed ashore in Mexico, is lying in a hospital bed from which he suggests that the details of the survival story told up to this point were, in fact, allegorical. In the alternate version, the one "without animals” (Martel, p. 303), as Pi refers to it, his original companions on the lifeboat are other humans: his own mother, a wounded sailor, and the ship's ruthless cook. It is first the cook who resorts to homicide and cannibalism in the face of hunger, and eventually it is Pi himself, who kills the cook - the murderer of Pi's mother - and eats his inner organs raw. In the interpretation provided within the narrative of the allegorical aspects of the first version of the story, the one with animals, it is suggested that Richard Parker, the tiger with the human name, stands for Pi himself, or rather, for the beast within that keeps this gentle and devout young boy alive, and that makes a killer, a carnivore and a cannibal out of him. Driven by an urge to survive, an urge to live, Pi owes his life to the beast within him, the one that suspends human, cultural norms and inner convictions in the name of survival.

But isn't Pi's experience, playing itself as thought, as the reader's own thought expressed in the first person, the equivalent of Jonas' permission, "for the sake of physical survival” (Jonas, 1996, p. 112), to suspend political and hence moral principles until the existential danger passes and morality can resume? In the allegorical terms of the novel, this is precisely what happens, as Richard Parker, the dangerous companion/animal within, disappears into the jungle once the lifeboat reaches shore, without even a departing glance at his human traveling mate, savior, and counterpart (Martel, 2001, pp. 284-5). Pi, having physically survived, can resume his pious life as a follower of three religions and become later a father and a family man in a household where animals are again pets and friends rather than enemies or food. The novel's framework narrator, who records and delivers, as it were, Pi's first person narration of his story, comments upon seeing the older Pi with his family and their cat and dog, "This story has a happy ending” (93). Such "happy ending” vindicates, so it seems, Jonas' position, and the terms of this allegorical narrative spell out that a temporary relinquishing of one's humanity in the face of mortal danger still allows one, later on, to survive as human. At the same time it shows that this suspension of morality is a suspension of identity, indeed that Pi Patel stops being just Pi Patel and becomes also Richard Parker, a killer tiger, an animal who resorts to animalistic acts, which, on the "literal" level of this tale, means a human being who kills and cannibalizes other humans.

Coming out of the fiction, we wonder if such a case of intermittent humanity can withstand our demand of surviving humanly, of responsible beings who do not cease being responsible without ceasing to be. This fictional story, which can find many parallel real-life tales of survival at times of war and strife, even as the details of the 
transgressions may vary, suggests that in actual experience, our hope for an existential ethic of unsuspended responsibility fails.

Or does it? If ethical principles often fail the test of life and death, as they seem to do in our fictional test case, did we not already realize that the setting of the ecological crisis demands also a different positioning of the ethical-existential problem? Indeed, entering the question of species survival within an inhabitable environment, we have already realized that here the terms of survival and its very scenario are different from the ones with which ethical codes usually fail, just as the scenario of personal survival in Life of $\mathrm{Pi}$ demonstrated again such failure. What is different is that the case of the concrete experience of this or that individual cannot serve as a helpful model for an ecological ethic.

Literature is already halfway within the phenomenological, in rendering possible experience into words and inserting these words into the reader's mind. The efficacy of this fictional literature lies in its insertion of the possible experience of an immediate mortal danger and the choices made - the choice to suspend the moral code and cultural ethos-when survival dictates the course. It demonstrates how a drive for life can drive one to murder, how close is the connection between vitality and mortality also in the case of the endangered individual, just as it is an ecological principle. But, this does not mean that with this story we receive the verification that an ethic of survival is impossible (i.e. that survival trumps all moral codes). Instead, it cautions us away from using the individual as model for an environmental ethic; it cautions phenomenology away from the model in which my experience becomes the measure of an ethic for species survival.

This becomes tricky, as we seem to be turning away from the individual towards a larger ecological whole; at the same time, we cannot relinquish the understanding of ethic as grounded in the individual. This leads us into our final discussion, focusing, this time, on the negotiation of the positions of the individual and of community in the context of an environmental ethic of survival.

\section{Community, Individuals, Sacrifice}

Sacrifice is the operative term in an ecological ethic demanded by an environmental crisis. For sacrifice here means limitation, the self-limitation that we need to introduce and practice in order to repair the dangerous ecological imbalance resulting from the absence of limits to human growth. Our discussion of Hans Jonas' notion of responsibility as an ethic of survival led to a conclusion, perhaps beyond the one explicitly stated by Jonas, that as a responsible being I would either have to sacrifice my life or I would have to sacrifice my self.

The first person singular used here is not only dictated by the mode of phenomenological investigation; our understanding of the ethical commandment requires it as 'first personal' by definition. As suggested earlier, ethics start from the individual, not because we are promoting a libertarian view that focuses solely on the individual's rights and freedoms, but because an ethic grounded in liberty and autonomy can only accept self-commandment as an ethical commandment. Obeying a moral commandment given by another, even if the other is the State or God, is mere obedience, whereas ethics means obeying moral commandments given by oneself. 
An ethical commandment is self-imposed in relation to others, as an ethic is defined as the mode of relating to others-it always traffics between the individual and the other, the individual and the larger community. The ethos of responsibility, the individualcommunity matrix, the communal "endangered future," the dramatic question of the survival of the species, the ecological model of wholes-all these lead to the question of the negotiation of a community-based ethic that focuses on the well-being of the larger social (or ecological) unit, and an individual-based ethic, which not only focuses on the freedom and existential rights of the individual, but also understands that an ethic operates through individuals and their actions. Eventually, it is only the individual who could be said to act ethically (obeying a self-commandment) and it is also only the individual who pays the ultimate price for the needs of other individuals or of the larger community: only individuals die.

If for the individual, sacrifice will always feature as self-sacrifice, for the community and in the mortal terms of an ethic-at-the-limit, sacrifice would always be the sacrifice of the lives of others. It is others who die while the community as a collectiveself survives. Sacrificing others, sacrificing the life of the other, even for the sake of the survival of the community, is not really sacrifice; it is closer to murder. It is a violation of the individual other and it is incompatible with an individual based ethic. Only a community-based ethic can lead to this, that is, to an ethically sanctioned murder.

An individual based ethic, then, is not simply focused on "egotism," as Kohák suggests (Kohák, 2000, p. 92). Among the two kinds of ethic, this is the one structured to prevent murder or protect community's individuals from premature death. This is the limit that an individual-based ethic would set to the common ethical goal of ensuring human survival into an indefinite future. We are starting to understand, I hope, that in the ethical context, the terms 'community' and 'individual' are mutually inclusive, the one dependent on the other. An ethic can only be practiced in a community of one kind or another, including the biotic community; it is the code of conduct between an ' $\mathrm{I}$ ' and others.

We conclude, then, that the ethics of responsibility must be practiced individually, even as it needs to be fostered collectively. An individual-based ethics does not only focus on the rights of the individual other, but also begins with the individual self, whose ethical commandment applies only to oneself rather than form a decree to others. As a moral individual, the self limits oneself in the name of morality, limits unto death, without demanding the same from others. What should I deem morally considerable? Everything. From whom should I demand moral responsibility? From myself only. Following my individual responsibility towards a larger community, distant from me in space and time, would direct me to cede and limit myself, without legislating for others my morality as law, even as I understand that the goal of species survival, the survival of humans as humans, would be achieved only through the collective fostering of an individually practiced ethic.

Finally, as a community, in collectively fostering responsibility and moving towards a culture of sacrifice, the ethical goal is never to reach the point in which it is life that is sacrificed, and this means the life of existing, living beings, contemporaries, rather than potential life. This would be the most practical of conclusions we can achieve here: in negotiating our ecological self-limitation, and specifically the necessary limitation to the growth of human population, we do not allow for a society to be formed in which the 
lives of others become negotiable, as that would betray the principle of human responsibility that we discover with the very realization of a collective existential threat.

\section{References}

Berry, T. (2000). The great work: Our way into the future. New York: Harmony/Bell Tower.

Birch, T. (1993). Moral considerability and universal consideration. Environmental Ethics, 15 (4), 313-332.

Brown, C. (2003). The real and the good. In C. Brown \& T. Toadvine (Eds.) EcoPhenomenology: Back to the earth itself (pp. 3-18). Albany, NY: SUNY Press.

Callicott, J. B. (1985). Intrinsic value, quantum theory, and environmental ethics. Environmental Ethics, 7, 257-275.

Callicott, J. B. (1992). Guest editor. The Monist, 75 (2).

Callicott, J. B. (1999). Beyond the Land Ethic: More Essays in Environmental Philosophy. Albany, NY: SUNY Press.

Goodpaster, K. (1978). On being morally considerable. Journal of Philosophy 75, 308325.

Heidegger, M. (1962). Being and time. (J. Macquarrie \& E. Robinson, Trans.). Oxford, UK: Basil Blackwell.

Iser, W. (1974). The implied reader. Baltimore: Johns Hopkins University Press.

Jonas, H. (1963/2001). The phenomenon of life. Evanston: Northwestern University Press.

Jonas, H. (1973). Technology and responsibility: Reflections on the new tasks of ethics. Social Research, 38 (4), 31-54.

Jonas, H. (1976). Responsibility today: The ethics of an endangered future. Social Research, 43 (1), 77-97.

Jonas, H. (1984). The imperative of responsibility: In search of an ethics for the technological Age. Chicago: The University of Chicago Press, 1984. German version: Das Prinzip Verantwortung: Versuch einer Ethik für der technologische Zivilisation. Frankfurt: Insel, 1979.

Jonas, H. (1996). Mortality and morality: A search for the good after Auschwitz. Evanston: Northwestern University Press. 
Kagan, S. (1998). Rethinking intrinsic value. The Journal of Ethics, 2 (4), 277-297.

Kohák, E. (2000). The green halo: A bird's-eye view of ecological ethics. Chicago: Open Court.

Krebs, A. (1999). Ethics of nature: A map. Berlin and New York: de Gruyter.

Leopold, A. (1949, 1987). A sand county almanac, and sketches here and there. New York: Oxford University Press.

Light, A. (2002). Contemporary environmental ethics from metaethics to public philosophy. Metaphilosophy, 33 (4), 426-449.

Light, A., \& Rolston, H. III. (2003). Environmental ethics: An anthology. Malden, MA \& Oxford, UK: Blackwell Publishing.

Martel, Y. (2001). Life of Pi: A novel. New York, San Diego, and London: Harcourt, Inc.

McShane, K. (2007). Why environmental ethics shouldn't give up on intrinsic value. Environmental Ethics, 29 (1), 43-61.

Meadows, D. H., Meadows, D. L., Randers, J., \& Behrens, W.III. (1972). The limits to growth: A report for the Club of Rome's project on the predicament of mankind. New York: Universe Books.

Moore, G.E. (1922). Philosophical studies, New York: Harcourt, Brace, \& Co.

Orlowski, J. and Aronson, J. (Producers) \& Orlowski, J. (Director). (2012). Chasing Ice [Motion picture]. United States: Submarine Deluxe.

Palmer, C. (2003). An overview of environmental ethics. In A. Light and H. Rolston (Eds.), Environmental ethics: An anthology. (pp. 15 -37). Malden, MA \& Oxford, UK: Blackwell Publishing.

Poulet, G. (1969). Phenomenology of reading. New Literary History , 1 (1), 53-68.

Regan, T. (1981). The nature and possibility of an environmental ethic. Environmental Ethics 3: 19-34.

Rolston, H., III. (1991). Environmental ethics: Values in and duties to the natural world. In F. H. Bormann and S. R. Kellert (Eds.), Ecology, economics, ethics: The broken circle. (pp. 73-96). New Haven: Yale University Press.

Rolston, H., III. (1999). Genes, genesis and God: Values and their origins in natural and human history. Cambridge, UK: Cambridge University Press. 
Routley, R. (1973). Is there a need for a new, an environmental ethic? Proceedings of the $15^{\text {th }}$ World congress of Philosophy, Vol. 1 pp. 205-10. Sophia: Sophia Press.

Safit, I. (Forthcoming). Nature screened: An eco-film-phenomenology. Environmental Philosophy.

Samuelsson, L. (2010). Reasons and values in environmental ethics. Environmental Values, 19, 517-35.

Wittgenstein, L. (2000). Tractatus Logico-Philosophicus. German text with an English translation by C. K Ogden. London and New York: Routledge. 